\section{Too much high-energy physics}

SIR - Your Washington correspondent reports (Nature 9 June, p.465) that Dr Keyworth, science adviser to President Reagan, upon being asked about the very strong adverse reaction of the entire materials research community to the Lawrence Berkeley Laboratory (L.BL) proposal for a National Center for Advanced Materials (NCAM), agreed that it was not the optimal step for the health of materials science, "but the issue is what is best for America in toto? Where you allocate federal resources is not a scientific issue but a matter of priorities".

I have had the rare privilege of spending a year as a scientist thinking precisely about the allocation of federal resources in the technical sector within an organization studying national policy making without the constraint of day-to-day decision making.

From that viewpoint this administra tion's science-policy decisions are a baffling crazy-quilt. My perception of the national priority is to reconfigure the total research and development effort into a much more efficient system to improve the rapidly declining position of the United States in useful science of all kinds and in most technologies, with the single exception of defence technology where the United States remains far ahead in sophistication. Restoring the health of the "midday" industries (those which are essential and used by large numbers food, materials, housing, transportation) which provide the main industrial employment base while also encouraging the "sunrise" ones could certainly constitute the focus of technology policy. Basic nonpurpose-linked science and our highest tech industries (Bell Labs, IBM and so on) are the bright spots in the American scene - probably needing the least help.

Yet the policies have been almost exactly the opposite. Destabilizing of the fragile bureaucracy for applied science by successive proposed and planned abolitions of the Departments of Energy, Education and Commerce. Proposed abolition of almost the best models of essential governmentled laboratories helping industrial research - the Fire and Building Centers at the National Bureau of Standards. Abolition of the National Science Foundation's science education directorate and at the same time enormous ( $\sim 20$ per cent) proposed increases in basic science budget and special initiatives such as LBL-NCAM.

Analysis of this pattern of "allocation of federal resources" clearly says the following about the Reagan Administration's priorities. It has no responsibility for the saving of American technology and the jobs dependent on it, it has no responsibility for either creating or partly redeploying science technical personnel away from the more esoteric sciences (presently forced by the federal budget allocations) to the equal- ly basic, considerably more difficult science relevant to real private and public sector technologies. The reasons for this, I believe, are human. For far too long the national science priorities in the United States have been made by the high-energy physics community. By sheer numbers, seniority, gratitude for the bob, false hopes in the star war victories, to say nothing of hubris, this community has rephrased General Motor's Engine Charlie's aphorism to read "what's good for physics is good for science and the nation",

Perhaps LBL-NCAM can become the first crack in this paradigm by proving that what may be good for physics has very little to offer materials science, and right now materials research is vastly more connected with national priorities of a healthy technology and more jobs than a sixth synchrotron light source. One lesson must not be forgotten by the materials community and all other applied science and engineering groups: if they don't aggressively make policy in their own fields for the national good, others innocent of any experience or knowledge of the field will do it for them.

The Brookings Institution,

Washington DC 20036, USA

\section{Farmers' help}

SIR - Nature is to be commended for its important editorial (23 June, p.645) concerning agricultural research policy in the United States. By pointing out that genetic science has the potential for reducing costs as well as increasing crop quantity, it hits a neglected nail squarely on the head and highlights new opportunities for improving farmers' income. This can help move urban-based policy makers beyond a simple minded focus on "yield".

Consider a plausible illustration: semiomolecules (loosely, "signalling-molecules") are produced by many plants and operate in a pheromone-like manner by causing insects and other pests to avoid the plants for feeding or egg laying. Suppose that functionally active semio-molecules, which are also strongly promoted singlegene products of suitably low molecular weight, can be ubiquitously expressed in host plant tissues through genetic engineering. Such an outcome in pest management via plant molecular and cellular biology could be several orders of magnitude more cost effective than traditional chemical approaches to formulating, manufacturing and applying biocides. A genetically engineered "non-preference" might also present a safer approach to the complex public health issue of toxicity.

While a number of challenges for genetics and ecology are raised by this hypothetical illustration, several interesting points could be made: (1) this type of technology is now foreseeable; (2) some polygenic hurdles might be side-stepped; and (3) the added value in this case may be one of cost reduction (eliminating the need for insecticide application), not of increased harvest index.

Other examples with far greater potential for farmers can be contemplated. All would require enhanced collaboration between traditional agricultural science disciplines and state-of-the-art biology and biochemistry. In any case, we should be helped if we refined our use of the word "yield" to mean Return On Investment rather than as a measure of gross biomass per acre.

Agrigenetics Corporation,

3375 Mitchell lane,

Boulder, Colorado 80301, USA

\section{Greek science}

SIR - In an interview by Robert Walgate with the Minister of Research and Technology, Professor G. Lianis, Mr Lianis states that one of his priorities will be "to sort out which scientists in the universities and the few research institutions in Greece are more or less political appointees of previous governments and which are doing real science'. Thus the impression is given that the research centres of Greece are political fiefdoms.

Concerning Demokritos, the largest of the "few research institutions", the statement of Minister Lianis is an accusation to which we vehemently object. The scientists employed at the Demokritos Nuclear Research Centre have been chosen on purely scientific criteria. Additionally, for at least the past fifteen years, all scientists at Demokritos have been appointed after the position has been properly advertised in the press and a scientific committee has examined the qualifications of each applicant. This is a procedure required by law. Furthermore, each scientist hired for the first time signs only a one year contract that can be renewed twice more before he acquires tenure.

The innuendos that good research has never taken place in Greece create another false impression. We wish to refer you to another article in Nature ${ }^{2}$, where a Nature travelling fellow visiting Greece states that "the factors contributing to Demokritos' success seem to be . . . the higher qualifications possessed by practically all scientific staff and good facilities".

We would also like to inform you that in a press release of our association published in the Athens newspaper Kathimerini (30 April 1983), a comparative study of Demokritos with other Western European national laboratories for the period 1979-81 reinforces the view expressed in your 1978 article. G. VOURVOPOULOS Demokritos Nuclear Research Centre, Aghia Paraskevi-Attikis, Athens, Greece

I. Nature 301, 363 (1983)

2. Pantelouris, E.M. Nature 271, 394 (1978). 